\title{
The Effect of Age and Comorbidities on the Association Between the Medicare STAR Oral Antihyperglycemic Adherence Metric and Glycemic Control
}

\author{
Gregory A. Nichols, PhD; Marsha A. Raebel, PharmD; Wendy Dyer, MS; and Julie A. Schmittdiel, PhD
}

\begin{abstract}
BACKGROUND: The Medicare STAR program for Medicare Advantage Plans that include drug benefits provides monetary incentives for health plans to achieve good adherence to oral antihyperglycemic (OAH) agents but does not account for differential case mix that could affect the ability of health plans to achieve the required quality metrics.

OBJECTIVE: To determine whether $\mathrm{OAH}$ adherence varies by age and comorbidities among patients aged 65 years or older and the extent to which adherence affects glycemic control across age and comorbidity strata.

METHODS: We studied 54,480 patients with diabetes aged $>65$ years from the Colorado, Northwest, and Northern California regions of Kaiser Permanente who received OAH agents but not insulin in 2010. We calculated adherence using the proportion of days covered (PDC) method. Per the STAR program, hemoglobin A1c $<8 \%$ defined good glycemic control. We also defined poor control as A1c $>9 \%$. We used modified Poisson regression to identify predictors of adherence and to determine its effects on A1C across age and comorbidity strata, adjusting for sociodemographics and medication-related variables.
\end{abstract}

RESULTS: The risk of being adherent to OAH declined moderately with an increasing number of comorbidities (risk ratio $[R R]=0.99$,

$95 \% \mathrm{Cl}=0.98-1.00$ for 1 comorbidity and $\mathrm{RR}=0.90,95 \% \mathrm{Cl}=0.88-0.91$ for 4 or more comorbidities). Adherence to $\mathrm{OAH}$ agents was associated with a $0 \%-3 \%$ increased risk of $A 1 \mathrm{C}<8 \%$ across age and comorbidity categories, as well as a large decreased risk ( $R R=0.55-0.73)$ of $A 1 \mathrm{c}>9 \%$ for patients aged $<80$ years or with $<3$ comorbidities.

CONCLUSIONS: Among patients with diabetes aged $>65$ years, having multiple comorbidities affects adherence. Adherence reduces the risk of poor A1c control among patients aged 65-79 years or with 2 or fewer comorbidities. Our results suggest that health plan case mix minimally influenced the Medicare STAR OAH adherence metric, but it may affect glycemic control quality measures, especially if a HEDIS-like measure of poor control were adopted.

J Manag Care Spec Pharm. 2018;24(9):856-61

Copyright @ 2018, Academy of Managed Care Pharmacy. All rights reserved.

\section{What is already known about this subject}

Better adherence to oral antihyperglycemics (OAHs) is associated with achievement of good glycemic control but has not been widely studied in the elderly.

The Centers for Medicare \& Medicaid Services added adherence metrics to their Medicare STAR program in 2012, thus providing financial incentives for health plans to achieve adherence to OAHs among patients with diabetes but does not adjust the adherence or glycemic control metrics for case mix.

\section{What this study adds}

Among patients with diabetes aged $>65$ years, having multiple comorbidities but not increased age affects adherence.

Adherence reduces the risk of poor hemoglobin Alc control among younger elderly (aged 65-79 years) or healthier elderly ( 2 or fewer comorbidities) patients.

Health plan case mix minimally influenced the Medicare STAR $\mathrm{OAH}$ adherence metric, but it may affect glycemic control quality measures, especially if a HEDIS-like measure of poor control were adopted.

$\mathrm{E}$ stimates of adherence to oral antihyperglycemic (OAH) agents range from as low as 36\% to as high as $93 \% .{ }^{1}$ Better adherence to OAHs is associated with achievement of good glycemic control and with decreased health care resource utilization. ${ }^{1-3}$ Improving or avoiding loss of adherence to diabetes drugs could lead to an annual cost saving of $\$ 8$ billion. ${ }^{4}$ On an individual patient level, those patients with poor adherence and high glycosylated hemoglobin Alc levels are less likely to have their medications intensified than patients with good adherence, suggesting that patient behavior influences clinician decision making. ${ }^{5}$

To date, medication adherence research has not typically focused on Medicare-aged populations. ${ }^{1}$ Nevertheless, in recognition of the potential effect of adherence to OAHs, the Centers for Medicare \& Medicaid Services (CMS) added adherence metrics to their Medicare STAR program for Medicare Advantage plans that include Medicare Part D in 2012, ${ }^{6,7}$ thus providing financial incentives for health plans to achieve adherence to $\mathrm{OAH}$ agents among patients with diabetes. Currently, none of 
the Medicare STAR metrics are adjusted for differences in the populations within each health plan. However, there is concern that the feasibility of achieving the STAR goals in patients with diabetes could vary depending on age, sex, comorbidities, and other factors that comprise differences in populations across participating health plans. These differences, known as patient case mix, could potentially result in inaccurate quality information. ${ }^{8}$ Our objective was to determine whether OAH adherence varies by 2 simple measures of case mix (age and number of comorbidities) and the extent to which adherence affects glycemic control by these measures of case mix.

\section{Methods}

We combined electronic health record (EHR) data from the Northern California, Colorado, and Northwest regions of Kaiser Permanente (KPNC, KPCO, and KPNW, respectively). These integrated delivery systems collectively currently serve more than 5 million individuals. To ensure that our data were not affected by the implementation of the Medicare STAR adherence metrics that occurred in 2012, we selected 2010 as the analysis year.

Using dispensing data linked to the EHR, we estimated adherence by proportion of days covered (PDC), defined as the percentage of days in the measurement period (2010) covered by prescription fills of the same medication or same therapeutic class. ${ }^{9}$ PDC ranges from 0 to 1 and is expressed in percentage terms of $0 \%-100 \%$. CMS provides specifications for calculating PDC for patients on OAH agents; patients are considered adherent if their PDCs are $\geq 80 \% .{ }^{7}$ Following CMS specifications, the measurement period began with the first fill in 2010 and continued through December 31, 2010.

For the current study, we identified all patients aged 65 years or older with at least 2 outpatient visits with an International Classification of Diseases, Ninth Revision, Clinical Modification diagnosis code of diabetes (250.xx) in 2010 or earlier, and then applied inclusion and exclusion criteria to mimic the subset of patients with diabetes who would be included in a health plan's calculation of the adherence metric. Specifically, patients were eligible if they were aged 65 years or older on January 1, 2010, and had an OAH dispensed at least twice $(\mathrm{N}=71,645)$. Of these, we excluded 15,016 patients because they also had insulin dispensed; such patients are not included in the assessment of adherence in the Medicare STAR program. For analysis purposes, we excluded another 2,149 patients because they had no Alc measurements in 2010. This exclusion resulted in a final study sample of 54,480 patients.

Also, in accordance with CMS specifications, we used the last Alc measured in 2010 to determine glycemic control. ${ }^{10}$ CMS defines good control as Alc $<8 \%$; we further defined poor control as Alc $>9 \%$. We examined adherence of $>80 \%$ as an outcome with age and number of comorbidities as the main independent variables, and also as a predictor of good and poor glycemic control in models stratified by age (65-69, $70-74,75-79,80+$ years) and number of comorbidities $(0,1,2$, $3,4+)$. To isolate the independent effect of age and comorbidities on adherence and the independent effect of adherence on glycemic control, we examined additional covariates, including sex, race/ethnicity, household income and education at the census block level, body mass index, diabetes treatment intensity (use of any injectable other than insulin or $\geq 2 \mathrm{OAH}$ medication classes with at least 1 at a high dose), medication burden (number of medication classes as of January 2010), mean days supply of OAHs during 2010, copayment for a 30-day supply of a generic drug, annual out-of-pocket maximum for health care services, and length of enrollment during 2010.

All analyses were conducted using Stata, version 12 (StataCorp, College Station, TX). We used modified Poisson regressions to model 3 outcomes: adherence to $\mathrm{OAH}$ medications (PDC $>80 \%$ ), good Alc control, and poor Alc control This method produced estimates of risk ratios (RR) and was appropriate when outcomes were common. ${ }^{11}$ The study was reviewed and approved by the KPNC Institutional Review Board; KPCO and KPNW ceded oversight to KPNC.

\section{Results}

Of the 54,480 patients included in the study, 48,803 (90\%) were in good glycemic control and 1,708 (3\%) were in poor glycemic control (Table 1). The remaining 3,969 (7\%) patients had Alc between $8 \%$ and $9 \%$. Those in good control were significantly more likely to be aged 70 years or older $(P<0.0001)$ and had a significantly higher mean number of comorbidities (1.6 vs. $1.5, P<0.0001$ ). Overall, $83 \%$ of the study sample met the Medicare STAR criterion for adherence to OAH medications (PDC $>80 \%)$. However, only $71 \%(n=1,213)$ of patients with poor glycemic control were adherent versus $83 \%(n=40,506)$ of those in good control $(P<0.001)$. Compared with patients with $\mathrm{Alc}<8 \%$, those with Alc $>9 \%$ were also more likely to be receiving high-intensity diabetes treatment (45\% vs. $27 \%$, $P<0.0001$ ), yet on average, were receiving fewer medications of all types ( $4 \pm 3$ vs. $6 \pm 3, P<0.0001)$

Column 1 of Table 2 displays the estimated RRs from the model, where adherence to OAHs is the dependent variable. Compared with the reference group patients aged 65-69 years, the group aged $>85$ years was significantly and negatively associated with being adherent $(\mathrm{RR}=0.98,95 \%$ confidence interval $[C I]=0.96-0.99$ ). There was an approximately linear negative relationship between the number of comorbidities and adherence. Compared with patients with no comorbidities, patients with 1 to 4 or more comorbidities were 1\%,3\%,6\%, and 10\% less likely to be adherent to OAHs, respectively.

The effect of adherence on achieving good glycemic control was small, with little variation across the age strata (column 2); adherent patients aged 65-69, 70-74, and 75-79 years were $2 \%$ more likely to be in good glycemic control, but there was 


\section{The Effect of Age and Comorbidities on the Association Between the Medicare STAR Oral Antihyperglycemic Adherence Metric and Glycemic Control}

\section{TABLE 1 Patient Demographic and Medication and Benefit-Related Characteristics}

\begin{tabular}{|c|c|c|c|c|c|}
\hline & \multirow[b]{3}{*}{ Total } & \multicolumn{3}{|c|}{ Glycemic Control $^{\mathrm{a}}$} & \multirow[b]{4}{*}{$P$ Value } \\
\hline & & Good & Intermediate & Poor & \\
\hline & & Alc $<8 \%$ & Alc $8 \%-8.9 \%$ & Alc $\geq 9 \%$ & \\
\hline $\mathrm{N}(\%)$ & $54,480(100 \%)$ & $48,803(90 \%)$ & $3,969(7 \%)$ & $1,708(3 \%)$ & \\
\hline \multicolumn{6}{|l|}{ Age categories (years) } \\
\hline $65-69$ & 33 & 32 & 38 & 41 & $<0.0001$ \\
\hline $70-74$ & 27 & 27 & 27 & 22 & $<0.0001$ \\
\hline $75-79$ & 20 & 20 & 17 & 18 & $<0.0001$ \\
\hline $80-84$ & 13 & 13 & 10 & 12 & $<0.0001$ \\
\hline $85 \pm$ & 7 & 7 & 7 & 7 & 0.2221 \\
\hline \multicolumn{6}{|l|}{ Number of comorbidities } \\
\hline 0 & 25 & 25 & 26 & 30 & $<0.0001$ \\
\hline 1 & 29 & 29 & 30 & 27 & 0.0332 \\
\hline 2 & 22 & 22 & 22 & 21 & 0.5244 \\
\hline 3 & 13 & 13 & 12 & 11 & 0.0039 \\
\hline $4 \pm$ & 11 & 11 & 10 & 11 & 0.0099 \\
\hline Mean (SD) number of comorbidities & $1.62(1.46)$ & $1.63(1.46)$ & $1.54(1.41)$ & $1.52(1.49)$ & $<0.0001$ \\
\hline Female & 48 & 49 & 45 & 48 & 0.0008 \\
\hline \multicolumn{6}{|l|}{ Race/ethnicity } \\
\hline Asian & 12 & 12 & 12 & 11 & 0.2506 \\
\hline Black & 7 & 7 & 7 & 9 & 0.0339 \\
\hline Native Hawaiian/Pacific Islander & 1 & 1 & 1 & 1 & 0.3003 \\
\hline Hispanic & 13 & 13 & 14 & 16 & 0.0009 \\
\hline Missing/unknown & 12 & 11 & 13 & 13 & 0.0008 \\
\hline American Indian/Alaska native & $<1$ & $<1$ & $<1$ & 1 & 0.0524 \\
\hline White & 55 & 56 & 53 & 50 & $<0.0001$ \\
\hline \multicolumn{6}{|l|}{ BMI $\left(\mathrm{kg} / \mathrm{m}^{2}\right)$} \\
\hline Underweight: $<18.5$ & $<1$ & $<1$ & $<1$ & $<1$ & 0.5355 \\
\hline Normal weight: $18.5-24.9$ & 18 & 18 & 16 & 18 & 0.0028 \\
\hline Overweight: $25-29.9$ & 34 & 35 & 34 & 30 & 0.0015 \\
\hline Obesity class I: $30-34.9$ & 23 & 23 & 24 & 21 & 0.0359 \\
\hline Obesity class II: $35-39.9$ & 12 & 12 & 12 & 12 & 0.9985 \\
\hline Obesity class III: $>40$ & 6 & 6 & 6 & 5 & 0.5156 \\
\hline Missing & 6 & 5 & 7 & 13 & $<0.0001$ \\
\hline 12 months enrollment in 2010 & 83 & 83 & 81 & 71 & $<0.0001$ \\
\hline Adherent to oral OAH drugs & 83 & 83 & 81 & 71 & $<0.0001$ \\
\hline Days supply per prescription & $90 \pm 18$ & $91 \pm 18$ & $87 \pm 22$ & $83 \pm 24$ & $<0.0001$ \\
\hline Number of medication classes & $6 \pm 3$ & $6 \pm 3$ & $5 \pm 3$ & $4 \pm 3$ & $<0.0001$ \\
\hline High-intensity diabetes treatment & 29 & 27 & 48 & 45 & $<0.0001$ \\
\hline Generic 30-day drug copayment & $\$ 7.53 \pm 5.14$ & $\$ 7.49 \pm 5.05$ & $\$ 7.86 \pm 6.26$ & $\$ 7.96 \pm 4.86$ & $<0.0001$ \\
\hline OAH refills via mail order & 43 & 43 & 38 & 29 & $<0.0001$ \\
\hline Annual out-of-pocket maximum & $\$ 2,112 \pm 1,104$ & $\$ 2,108 \pm 1,104$ & $\$ 2,155 \pm 1,098$ & $\$ 2,125 \pm 1,123$ & 0.0763 \\
\hline Census: household income & $\$ 73,069 \pm 31,947$ & $\$ 73,314 \pm 32,023$ & $\$ 71,568 \pm 31,359$ & $\$ 69,570 \pm 30,816$ & $<0.0001$ \\
\hline Census: college graduate & 33 & 33 & 32 & 31 & $<0.0001$ \\
\hline
\end{tabular}

no significant effect on the strata of patients aged 80-84 and $>85$ years. Similarly, there was a small effect ranging from $1 \%$ to $3 \%$ for those with 2 or fewer comorbidities, but not a significant effect among those with 3 or 4 or more comorbidities. However, as shown in column 3 , adherence to OAHs reduced the risk of poor glycemic control among those patients aged
65-69（RR=0.73,95\% CI =0.58-0.91), 70-74（RR=0.55, 95\% $\mathrm{CI}=0.41-0.76)$, and $75-79$ years $(\mathrm{RR}=0.59,95 \% \mathrm{CI}=0.44$ 0.78). Adherence also had a large effect on avoiding poor control among patients with no comorbidities $(\mathrm{RR}=0.58$, $95 \% \mathrm{CI}=0.46-0.74), 1$ comorbidity $(\mathrm{RR}=0.72,95 \% \mathrm{CI}=0.54$ 0.95 ), or 2 comorbidities ( $R R=0.65,95 \% C I=0.48-0.88$ ); the 


\section{The Effect of Age and Comorbidities on the Association Between the Medicare STAR Oral Antihyperglycemic Adherence Metric and Glycemic Control}

\begin{tabular}{|c|c|c|c|c|}
\hline & & $\begin{array}{l}\text { Modified Po } \\
\text { Probability } \\
\text { Effect of Adr } \\
\text { Glycemic Co } \\
\text { Poor Glycem }\end{array}$ & $\begin{array}{l}\text { On Regres } \\
\text { OAH Adhe } \\
\text { rence on } \\
\text { trol, and th } \\
\text { Control }\end{array}$ & $\begin{array}{l}\text { is of the } \\
\text { ce, the } \\
\text { ining Good } \\
\text { isk of }\end{array}$ \\
\hline & $\begin{array}{l}\text { Sample } \\
\text { Size, n }\end{array}$ & $\begin{array}{l}\text { Adjusted }^{\mathrm{a}} \\
\text { Probability of } \\
\text { Adherence }\end{array}$ & $\begin{array}{l}\text { Adjusted }^{\mathrm{b}} \\
\text { Likelihood of } \\
\text { Alc }<8 \%\end{array}$ & $\begin{array}{c}\text { Adjusted }^{b} \\
\text { Risk of } \\
\text { Alc }>9 \% \\
\end{array}$ \\
\hline Age (ye: & & & & \\
\hline $65-69$ & 17,823 & reference & $1.02(1.00-1.03) \mathrm{c}$ & $0.73(0.58-0.91)$ \\
\hline $70-74$ & 14,782 & $1.00(0.99-1.01)$ & $1.02(1.01-1.04)$ & $0.55(0.41-0.76)$ \\
\hline $75-79$ & 10,897 & $1.00(0.99-1.01)$ & $1.02(1.00-1.04)^{\mathrm{c}}$ & $0.59(0.44-0.78)$ \\
\hline $80-84$ & 6,966 & $0.99(0.98-1.01)$ & $1.00(0.98-1.02)$ & $0.91(0.62-1.32)$ \\
\hline $85+$ & 4,012 & $0.98(0.96-0.99)$ & $1.01(0.98-1.03)$ & $1.18(0.70-2.01)$ \\
\hline Comorb & lities & & & \\
\hline 0 & 13,739 & reference & $1.03(1.01-1.05)$ & $0.58(0.46-0.74)$ \\
\hline 1 & 15,808 & $0.99(0.98-1.00)$ & $1.01(1.00-1.03)^{\mathrm{c}}$ & $0.72(0.54-0.95)$ \\
\hline 2 & 11,932 & $0.97(0.96-0.98)$ & $1.02(1.00-1.04)^{c}$ & $0.65(0.48-0.88)$ \\
\hline 3 & 7,131 & $0.94(0.93-0.96)$ & $1.00(0.98-1.02)$ & $0.80(0.53-1.20)$ \\
\hline $4+$ & 5,870 & $0.90(0.88-0.91)$ & $0.99(0.97-1.01)$ & $1.12(0.72-1.75)$ \\
\hline $\begin{array}{l}\text { median } \\
\text { full versu } \\
{ }^{2} \text { Model } a \\
\text { enrollme } \\
\text { Results } b \\
\text { comorbid } \\
{ }^{2} \text { Lower b } \\
\text { Alc }=\text { hen } \\
H M O=h\end{array}$ & $\begin{array}{l}\text { ehold in } \\
\text { artial en } \\
\text { sted for } \\
\text { uring } 2 \\
\text { ge strata } \\
\text { strata } \mathrm{fl} \\
\text { d of con } \\
\text { lobin Al }\end{array}$ & $\begin{array}{l}95 \% \text { CI. } \\
\text { racelethnicity, me } \\
\text { eneric drug copayr } \\
\text { ne and education } \\
\text { ment in } 2010 \text {. } \\
\text { racelethnicity, ov } \\
\text { mean days supply } \\
\text { ther adjusted for } \\
\text { er adjusted for ag } \\
\text { nce interval is }>1 \\
3 \mathrm{MI}=\text { body mass in } \\
\text { ince organization; }\end{array}$ & $\begin{array}{l}\text { nt, annual out-of } \\
\text { the census block } \\
\text { Il number of med } \\
\text { OAHs, and inte } \\
\text { mber of comorbid } \\
\text { but appears as } \\
x ; C I=\text { confidence } \\
\text { AH = oral antihyp }\end{array}$ & $\begin{array}{l}\text { Hs, BMI, use of } \\
\text { cket maximum, } \\
l, \text { HMO site, and } \\
\text { tions, length of } \\
\text { ty of treatment. } \\
\text { s. Results by } \\
\text { o due to rounding. } \\
\text { terval; } \\
\text { lycemic. }\end{array}$ \\
\hline
\end{tabular}

relationships between adherence and poor glycemic control for patients with 3 or 4 or more comorbidities were not statistically significant.

\section{Discussion}

In this retrospective analysis of 54,480 elderly patients with type 2 diabetes, we found that more than $80 \%$ were adherent to their OAH medications and that more than $90 \%$ had Alc levels $<8 \%$. Age had little effect on OAH adherence, and an increasing number of comorbidities only marginally affected $\mathrm{OAH}$ adherence. Furthermore, the effect $\mathrm{OAH}$ adherence on the likelihood of good glycemic control was small but was not identical across stratifications of age and number of comorbidities. These findings suggest that the ability of Medicare Advantage plans to achieve STAR reimbursement could well differ depending on case mix. Importantly, among patients aged $<80$ years or with $<3$ comorbidities, OAH adherence was associated with a substantial reduction in risk of poor glycemic control.

The overarching goal of the CMS STAR program is to reward Medicare Advantage health plans for high quality care. One measure of quality is achievement of good glycemic control for people with diabetes, but currently there is no counterbalancing measure of poor glycemic control. A recent study of elderly patients in the Veterans Affairs health system showed that quality rankings can vary substantially when comparing the standard measure $(\mathrm{Alc}<8 \%)$ to an out-of-range measure (Alc $<7 \%$ or $>9 \%$ ) across facilities. ${ }^{12}$ Considering Alc $<7 \%$ to be out-of-range is controversial, ${ }^{13}$ but there is no debate that Alc $>9 \%$ is undesirable. Because we found a substantial effect of adherence on risk of poor glycemic control, our data support the inclusion of Alc $>9 \%$ as an additional quality measure, especially in the context of medication adherence.

Adherence as a quality measure was introduced by CMS in 2012 to reward health plans for monitoring and improving adherence in their Medicare Advantage populations. ${ }^{6,7}$ This policy recognizes that adherence is much more than just a patient behavior by holding health plans accountable for policies and system-level factors that influence patient adherence. Our results show small and relatively uniform effect of age and number of comorbidities on adherence. Although older age is often associated with better adherence in general populations with diabetes, ${ }^{14}$ data on the association between age and adherence among the elderly are scant. ${ }^{10}$ The limited research-to-date on the relationship between adherence to diabetes medications and number of comorbid conditions has been equivocal. ${ }^{15}$ Our findings are consistent with studies showing associations in general populations with diabetes between age and comorbidities and adherence when considered univariately, ${ }^{16,17}$ but that those associations become minimal in multivariate analyses. ${ }^{10}$

We found that $\mathrm{OAH}$ adherence had a small effect on achievement of good glycemic control in patients aged 65-79 years, but no effect among the older age groups. Most studies demonstrate that better $\mathrm{OAH}$ adherence is associated with better glycemic control. ${ }^{1}$ However, even when the association is present, the effect is weak; a $10 \%$ increase in adherence has been associated with a $0.1 \%-0.3 \%$ decrease in Alc. ${ }^{1,18,19}$ To our knowledge, previous studies have not directly assessed the association between adherence and poor glycemic control. In our study, we found a strong association that was isolated to people aged $>65$ and $<79$ years or with 2 or fewer comorbidities. This finding suggests that the effect of adherence on poor control is only meaningful when the medical burden of a patient with diabetes is relatively low; the effect of adherence may be overwhelmed by other factors as the medical burden increases and patients enter their 80s.

Medication adherence has been described as a complex set of "interacting behaviors influenced by individual, social, and environmental factors." ${ }^{\prime \prime} \mathrm{A}$ recent large systematic review demonstrated that diabetes medication adherence is affected by demographic and clinical characteristics, including a variety of comorbidities, as well as health system characteristics. ${ }^{15}$ Many of these same characteristics also affect intermediate outcomes such as glycemic control. ${ }^{1}$ Because our objective was to explore how 
differences in populations of Medicare Advantage members influence the achievement of Medicare STAR metrics, we limited our evaluation to 2 simple measures of population differences (age and number of comorbidities). Several studies have demonstrated that case-mix adjustment of quality measures can dramatically affect performance assessment. ${ }^{20-22}$

More complex measures were beyond the scope of the current study, but would likely be necessary to balance the ability of health plans to achieve quality metrics in spite of population differences. If the Medicare STAR program were to adopt a risk-adjustment methodology, careful consideration would need to be given to the many factors that influence adherence and glycemic control. It should be noted that risk adjustment is not new to Medicare; after considerable study and delay, CMS began risk adjusting capitated payments to Advantage plans in $2004 .{ }^{23}$ Risk adjustment of Medicare STAR measures, however, is not currently done.

\section{Limitations}

Our study has the usual limitations of observational research, including the inability to infer causality from the associations we report. Although our sample represents 3 distinct regions of the United States, our findings may not be generalized to other geographic areas or to other health plans with fewer information technology resources designed to assist clinicians in attaining quality goals. Our Medicare populations may also have characteristics that differ from those in other health care settings. We intentionally limited our sample to patients with diabetes taking $\mathrm{OAH}$ medications but not insulin to mirror the sample used to calculate the Medicare STAR adherence metric. Excluding such patients has been shown to exclude $27 \%$ of patients with diabetes receiving OAH medications and to underestimate the prevalence of nonadherence. ${ }^{7}$ This may contribute to the high adherence rates reported herein (83\%), but that is not outside the range (38\%-93\%) reported in a 2015 systematic review. ${ }^{15}$

\section{Conclusions}

CMS considers the Medicare STAR metric for OAH adherence to be a quality measure; however, it is not currently adjusted for patient case mix. Our data suggest that simple representations of case mix (age and number of comorbidities) either do not or only marginally affect the adherence metric itself, but that adherence is differentially associated with poor glycemic control across age and comorbidity strata. The ability of Medicare Advantage plans to achieve STAR reimbursement may differ depending on case mix. Therefore, case-mix adjustment may be necessary for at least some quality metrics to equitably apply to Medicare Advantage health plans.

\section{Authors}

GREGORY A. NICHOLS, PhD, Kaiser Permanente Northwest Center for Health Research, Portland, Oregon, and MARSHA A. RAEBEL, PharmD, Kaiser Permanente Colorado Institute for Health Research, Denver. WENDY DYER, MS, and JULIE A. SCHMITTDIEL, PhD, Kaiser Permanente Northern California Division of Research, Oakland.

AUTHOR CORRESPONDENCE: Gregory A. Nichols, PhD, Center for Health Research, 3800 N. Interstate Ave., Portland, OR 97227-1098. Tel.: 503.335.6733; E-mail: greg.nichols@kpchr.org.

\section{DISCLOSURES}

This study was supported by grant number 1R21DK103146-01Al from the National Institute of Diabetes and Digestive and Kidney Disorders. Nichols currently receives grant funding from Boehringer-Ingelheim, Sanofi, Amarin Pharma, and Janssen Pharmaceuticals for other unrelated research projects The other authors declare no conflicts of interest.

This study was presented at the American Diabetes Association's 77th Scientific Sessions; June 9-13, 2017; San Diego, CA.

\section{REFERENCES}

1. Asche C, LaFleur J, Conner C. A review of diabetes treatment adherence and the association with clinical and economic outcomes. Clin Ther 2011;33(1):74-109

2. Pladevall M, Williams LK, Potts LA, Divine G, Xi H, Lafata JE. Clinical outcomes and adherence to medications measured by claims data in patients with diabetes. Diabetes Care. 2004;27(12):2800-05

3. Jha AK, Aubert RE, Yao J, Teagarden JR, Epstein RS. Greater adherence to diabetes drugs is linked to less hospital use and could save nearly $\$ 5$ billion annually. Health Aff (Millwood). 2012;31(8):1836-46.

4. Brown BG, Taylor AJ. Does ENHANCE diminish confidence in lowering LDL or in ezetimibe? N Engl J Med. 2008;358(14):1504-07.

5. Grant R, Adams AS, Trinacty CM, et al. Relationship between patient medication adherence and subsequent clinical inertia in type 2 diabetes glycemic management. Diabetes Care. 2007;30(4):807-12.

6. Steiner JF. Rethinking adherence. Ann Intern Med. 2012;157:580-85.

7. Schmittdiel J, Nichols G, Dyer W, Steiner J, Karter A, Raebel M. Medicare STAR excludes diabetes patients with poor CVD risk factor control. Am J Manag Care. 2014;20(12):e581-81.

8. Calsbeek H, Markhorst JG, Voerman GE, Braspenning JC. Case-mix adjustment for diabetes indicators: a systematic review. Am J Manag Care. 2016;22(2):e45-52.

9. Raebel MA, Schmittdiel J, Karter AJ, Konieczny JL, Steiner JF Standardizing terminology and definitions of medication adherence and persistence in research employing electronic databases. Med Care. 2013;51 (8 Suppl 3):S11-21.

10. Schmittdiel JA, Nichols GA, Dyer W, Steiner JF, Karter AJ, Raebel MA. Health care system-level factors associated with performance on Medicare STAR adherence metrics in a large, integrated delivery system. Med Care. 2015;53(4):332-37.

11. Zou G. A modified poisson regression approach to prospective studies with binary data. Am J Epidemiol. 2004;159(7):702-06.

12. Pogach L, Tseng CL, Soroka O, Maney M, Aron D. A proposal for an out-of-range glycemic population health safety measure for older adults with diabetes. Diabetes Care. 2017:40(4):518-25. 


\section{The Effect of Age and Comorbidities on the Association Between the Medicare STAR Oral Antihyperglycemic Adherence Metric and Glycemic Control}

13. Bloomgarden ZT, Einhorn D, Handelsman Y. Is HbAlc $<7 \%$ a marker of poor performance in individuals $>65$ years old? Diabetes Care. 2017;40(4):526-28

14. Ali MK, McKeever Bullard K, Imperatore G, Barker L, Gregg EW. Characteristics associated with poor glycemic control among adults with self-reported diagnosed diabetes-National Health and Nutrition Examination Survey, United States, 2007-2010. MMWR. 2012;61 (2 Suppl):32-37.

15. Krass I, Schieback P, Dhippayom T. Adherence to diabetes medication: a systematic review. Diabet Med. 2015;32(6):725-37.

16. Cramer JA. A systematic review of adherence with medications for diabetes. Diabetes Care. 2004;27(5):1218-24.

17. Amutha A, Anjana RM, Venkatesan U, et al. Incidence of complications in young-onset diabetes: comparing type 2 with type 1 (the young diab study). Diabetes Res Clin Pract. 2017;123:1-8.

18. Rozenfeld Y, Hunt JS, Plauschinat C, Wong KS. Oral antidiabetic medication adherence and glycemic control in managed care. Am J Manag Care. 2008;14(2):71-75
19. Kelly K, Grau-Sepulveda MV, Goldstein BA, et al. The agreement of patient-reported versus observed medication adherence in type 2 diabetes mellitus (T2DM). BMJ Open Diabetes Res Care. 2016;4(1):e000182.

20. Safford MM, Brimacombe M, Zhang Q, et al. Patient complexity in quality comparisons for glycemic control: an observational study. Implement Sci. 2009;4:2.

21. Zhang Q, Safford M, Ottenweller J, et al. Performance status of health care facilities changes with risk adjustment of HbAlc. Diabetes Care. 2000;23(7):919-27.

22. Abraham JM, Marmor S, Knutson D, Zeglin J, Virnig B. Variation in diabetes care quality among medicare advantage plans: understanding the role of case mix. Am J Med Qual. 2012;27(5):377-82

23. Weissman JS, Wachterman M, Blumenthal D. When methods meet politics: how risk adjustment became part of Medicare managed care. J Health Polit Policy Law. 2005;30(3):475-04. 